\title{
EFISIENSI ANGGOTA BURSA GUNA MENINGKATKAN DAYA SAING BISNIS PADA ERA MASYARAKAT EKONOMI ASEAN
}

\author{
THE EFFICIENCY OF SECURITY COMPANY MEMBERS (BROKERS)
}

TO INCREASE COMPETITIVENESS IN ASEAN ECONOMICS SOCIETY

\section{Muhammad Rifqi Syauqi ${ }^{* 1}$, Dedi Budiman Hakim**), dan Hendro Sasongko***)}

${ }^{*}$ Divisi Riset dan Pengembangan Bursa Efek Indonesia

\author{
Gedung Bursa Efek Indonesia Tower I Lt. 4, Jl. Jend. Sudirman Kav. 52-53 Jakarta 12190 \\ ${ }^{* *}$ Departemen Ilmu Ekonomi, Fakultas Ekonomi dan Manajemen, Institut Pertanian Bogor \\ JJl. Agatis Kampus IPB Darmaga, Bogor 16680 \\ $\left.{ }^{* * *}\right)$ Fakultas Ekonomi, Universtas Pakuan \\ Jl. Pakuan PO Box 452 Bogor 16143
}

\begin{abstract}
Capital market could provide better financing for companies and offer prospective investment for public. However, capital market has not fully absorbed the potential economics in Indonesia. The efficiency of Securities Company (brokers) in Indonesia should be optimized by the regulator to be able to compete with that from other countries. This paper measured the efficiency level of brokers and their effect on business competitiveness by using the Data Envelopment Analysis (DEA) approach and the regression model. The results found that the efficiency of brokers was relatively low i.e. approximately 0,22. The vast number of brokers with limited capital caused this low efficiency. Brokers with larger-scale companies have a higher efficiency than the smaller ones. The joint venture brokers are relatively efficient, for they usually have large capital. The minimum requirement of Net Adjusted Working Capital (NAWC) is insufficient to strengthen the competitiveness of brokers, and it should be increased from Rp25 billion to Rp100 billion. The increase in this capital is expected to encourage brokers to become more competitive in ASEAN market.
\end{abstract}

Keywords: Competitiveness, Data Envelopment Analysis (DEA), efficiency, Indonesia Stock Exchange (IDX), securities company

\begin{abstract}
Abstrak: Pasar modal belum sepenuhnya optimal memanfaatkan potensi ekonomi Indonesia. Perbankan masih menjadi sumber utama penggerak ekonomi padahal pasar modal menyediakan pilihan yang lebih baik dalam memenuhi kebutuhan pembiayaan perusahaan maupun intsrumen investasi bagi masyarakat. Rendahnya efisiensi Anggota Bursa (AB) dalam menjalankan bisnis transaksi efek perlu diperhatikan regulator agar pasar modal Indonesia mampu bersaing dengan negara lain. Penelitian ini melihat tingkat efisiensi AB dan pengaruhnya terhadap daya saing bisnis transaksi efek melalui Data Envelopment Analysis (DEA) dan model regresi. Berdasarkan hasil analisis diperoleh bahwa efisiensi AB masih rendah sekitar 0,22. Banyaknya AB bermodal terbatas menyebabkan rendahnya efisiensi ini. AB dengan skala perusahaan lebih besar memiliki efisiensi lebih tinggi dibandingkan $\mathrm{AB}$ yang skalanya kecil. $\mathrm{AB}$ joint venture tentu relatif efisien karena biasanya memiliki modal yang besar. Persyaratan minimum Modal Kerja Bersih Disesuaikan (MKBD) dinilai belum cukup memperkuat daya saing AB dan sebaiknya ditingkatkan dari Rp25 miliar menjadi Rp100 miliar sesuai hasil estimasi dengan model regresi. Kenaikan MKBD ini diharapkan mendorong AB agar lebih kompetitif dan mampu menguasai pasar di kawasan ASEAN.
\end{abstract}

Kata kunci: Bursa Efek Indonesia (BEI), Data Envelopment Analysis (DEA), daya saing, efisiensi, perusahaan sekuritas

\footnotetext{
${ }^{1}$ Alamat Korespondensi:

Email: rifqi.syauqi@idx.co.id
} 


\section{PENDAHULUAN}

Besarnya potensi ekonomi di Indonesia belum dimanfaatkan secara optimal untuk perkembangan pasar modal. Banyaknya perusahaan tercatat (emiten) yang bagus selayaknya mampu meningkatkan daya saing Bursa Efek Indonesia (BEI) dengan bursa di kawasan ASEAN. Perbandingan kondisi bursa di kawasan regional dapat dilihat pada Tabel 1 .

Pada kenyataannya, nilai transaksi saham di BEI kalah dengan bursa lain, seperti Stock Exchange of Thailand, Singapore Exchange, Bursa Malaysia. Hal ini diduga oleh kurang optimalnya fungsi Anggota Bursa (AB) dalam memanfaatkan peluang investasi di Indonesia. Banyaknya perusahaan dalam suatu industri akan menentukan tingkat persaingan (Diana, 2010). $\mathrm{AB}$ pada jumlah tertentu akan meningkatkan kualitas perusahaan dan menciptakan industri yang kompetitif. Bursa yang nilai transaksinya besar, proporsi jumlah emiten dengan $\mathrm{AB}$ mencapai 15 emiten/AB sementara $\mathrm{BEI}$ proporsinya relatif kecil (4,7 emiten/AB).

Anggota Bursa (AB) yang belum optimal memanfaatkan dan mengembangkan potensi pasar modal di Indonesia bisa menjadi suatu titik lemah. Hal ini diketahui dari banyaknya $\mathrm{AB}$ yang memiliki modal terbatas sehingga kurang maksimal dalam menangani transaksi efek. Modal yang cukup besar membantu perusahaan untuk melakukan ekspansi usaha dan menekan biaya operasional(Agus, 2011). Data Modal Kerja Bersihyang Disesuaikan (MKBD) menunjukkan bahwa mayoritas tersebar pada nilai yang relatif minim (Rp25-100 M). Selain itu, sebagian besar nilai transaksi saham di BEI dari beberapa AB (efek pareto) seperti pada Gambar 1.

Peranan $\mathrm{AB}$ sangat penting bagi BEI karena bertugas melayani investor dalam jual/beli saham yang diterbitkan emiten. Persaingan usaha antar AB terutama yang skalanya kecil menjadi kurang sehat akibat kurangnya inovasi (kesamaan layanan) dan kecilnya segmen pasar. Efisiensi menjadi salah satu inisiatif memperkuat daya saing pasar modal Indonesia. Oleh karena itu, penelitian ini mengulas efisiensi $A B$ di Indonesia guna meningkatkan daya saing bisnis pada era Masyarakat Ekonomi ASEAN (MEA).

Konsep MEA untuk pasar modal didorong untuk membentuk satu pasar dan basis produksi (single market and production base). Persaingan yang terjadi di ASEAN berupa kebebasan investor berinvestasi di mana saja dan broker boleh melakukan bisnis di negara lain. Salah satu yang ingin dicapai OJK dan BEI adalah penguatan $\mathrm{AB}$ mengingat jumlahnya terlalu banyak dan modalnya masih terbatas. Setidaknya ada dua pilihan untuk memperkuat $\mathrm{AB}$, yakni meningkatkan MKBD atau mendorong $\mathrm{AB}$ untuk merger (Aris, 2016).

Pasar modal memiliki peranan penting dalam susunan perekonomian suatu negara. Selain dana dari perbankan, perusahaan dapat memperoleh modal untuk mengembangkan bisnisnya melalui pasar modal. Kebutuhan modal tersebut dapat dipenuhi dengan menawarkan penyertaan kepemilikan (saham) atau menerbitkan surat hutang (obligasi) kepada publik. Saham dan obligasi yang dikeluarkan oleh perusahaan termasuk intrumen investasi yang umumnya digunakan dalam proses pengelolaan keuangan baik individu maupun institusi. Masyarakat pemilik dana (investor) boleh menempatkan uangnya pada saham atau obligasi yang tersedia di pasar modal guna memperoleh kesempatan menikmati pertumbuhan nilainya.

Besarnya potensi investasi di BEI yang dilihat dari kinerja indeks saham dan jumlah emiten yang berkualitas ternyata belum banyak menarik minat masyarakat untuk menjadi investor di pasar modal. Penambahan investor setiap tahun masih kurang signifikan padahal kegiatan edukasi terus dilakukan secara periodik dan masif. Aktivitas transaksi cenderung stagnan bahkan nilainya mengalami tren penurunan dalam tiga tahun terakhir. Hal ini diduga karena kurang optimalnya fungsi $\mathrm{AB}$ dalam memanfaatkan peluang investasi saham di Indonesia. Selain itu, daya saing (modal) $\mathrm{AB}$ masih terbatas apabila dibandingkan dengan perbankan.

Menurut Porter (1985), efisiensi merupakan strategi bersaing yang sesuai digunakan pada pasar yang umum dengan produk yang hampir sama. Strategi ini mendorong BEI untuk menekan alokasi sumber daya yang kurang optimal agar memperoleh keunggulan kompetitif pada era MEA. Harapannya biaya terkait pembinaan dan pengembangan $\mathrm{AB}$ turun tanpa mengurangi kualitas pelayanan terhadap investor. Dengan begitu, strategi efisiensi dapat memperkuat daya saing perusahaan. Selain itu, penerapan tata kelola perusahaan yang baik (good corporate governance) juga berpengaruh terhadap kepercayaan publik yang mendukung peningkatan daya saing perusahaan (Devita, 2011). 
Tabel 1. Perbandingan kondisi bursa di kawasan regional tahun 2015

\begin{tabular}{llcccc}
\hline & \multicolumn{1}{c}{ Bursa } & AB & Emiten & Nilai Transaksi (juta USD) & Proporsi Emiten : AB \\
\hline BEI & Bursa Efek Indonesia & 110 & 521 & 105.467 & 4,7 \\
BM & Bursa Malaysia & 30 & 902 & 129.823 & 30,1 \\
SGX & Singapore Exchange & 26 & 769 & 203.413 & 29,6 \\
SET & Stock Exchange of Thailand & 37 & 639 & 296.711 & 17,3 \\
PSE & Philipine Stock Exchange & 132 & 265 & 47.370 & 2,0 \\
HOSE & Hochiminh Stock Exchange & 91 & 307 & 22.005 & 3,4 \\
\hline
\end{tabular}

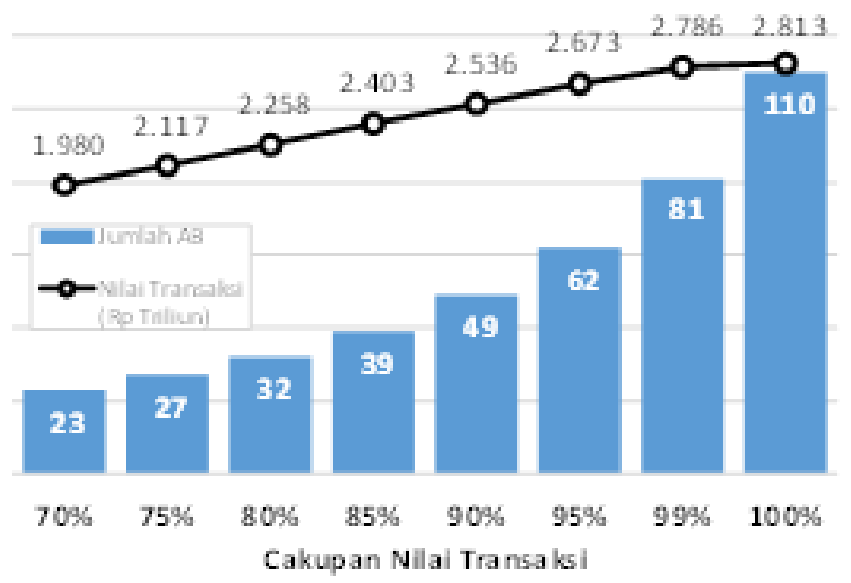

Gambar 1 Nilai transaksi sejumlah AB

Tujuan yang ingin dicapai dalam penelitian ini, antara lain: menentukan efisiensi dan menganalisis hubungannya dengan tingkat daya saing bisnis $\mathrm{AB}$ serta merumuskan batasan modal yang kompetitif pada era MEA. Hasilnya diharapkan dapat berguna bagi beberapa pihak terkait terutama regulator sebagai bahan pertimbangan untuk menyusun kebijakan. Selain itu, masyarakat (calon investor) terbantu dalam menentukan broker. Secara akademis, penelitian ini berpotensi dikembangkan untuk wawasan keilmuan yang luas.

Ruang lingkup dalam penelitian ini meliputi pembahasan daya saing bisnis transaksi efek di Indonesia akan difokuskan pada entiti $\mathrm{AB}$ berdasarkan aspek keuangannya. AB dianggap memiliki hubungan lebih erat dengan aktivitas perdagangan saham dibandingkan emiten atau investor. Peranan $\mathrm{AB}$ sebagai perantara pedagang efek sangat penting bagi BEI karena bertugas melayani investor dalam jual/beli saham yang diterbitkan emiten. Selain itu, AB juga berada dalam kontrol BEI sebagai regulator sehingga kebijakan yang akan direkomendasikan diharapkan dapat terealisasikan dengan baik. Efisiensi AB dipilih sebagai topik penelitian seiring dengan berlakunya pasar bebas ASEAN yang menuntut lembaga keuangan di Indonesia bersaing dengan negara lain.

\section{METODE PENELITIAN}

Penelitian ini menggunakan data dari BEI berupa laporan keuangan, MKBD, dan nilai transaksi saham per AB. Data tersebut disusun secara runtun waktu (time series) selama tahun 2015-2016 yang dibagi menjadi empat periode, yakni Triwulan 1 (JanuariMaret), Triwulan 2 (April-Juni), Triwulan 3 (JuliSeptember), dan Triwulan 4 (Oktober-Desember) sehingga terkumpul tujuh series data. Jumlah AB aktif yang mengirimkan laporan keuangan secara lengkap selama Triwulan 1 tahun 2015 s.d Triwulan 3 tahun 2016 ada $97 \mathrm{AB}$. Inisiatif penguatan $\mathrm{AB}$ disajikan dalam kerangka pemikiran pada Gambar 2.

Pengukuran efisiensi perusahaan dapat dilakukan dengan berbagai metode, salah satunya Data Envelopment Analysis (DEA) yang dibangun berdasarkan observasi populasi dan mengevaluasi efisiensi relatif terhadap objek pengamatan. Abidin dan Endri (2009), DEA adalah metode frontier non parametrik berdasarkan model linier untuk menghitung rasio output dan input semua unit yang dibandingkan dalam populasi. Subandi dan Ghozali (2013) menyatakan pendekatan non parametrik tidak memerlukan informasi, asumsi, dan sampel yang banyak. Kelemahannya, satu outlier memengaruhi nilai efisiensi dari setiap perusahaan (Hadad et al. 2003). Model DEA dengan pendekatan Constant Return to Scale (CRS) dipilih karena setiap $\mathrm{AB}$ diasumsikan beroperasi pada tingkat yang optimal dan memiliki kesempatan yang sama terhadap akses sumber daya. Pengelolaan sumber daya $\mathrm{AB}$ dapat dilihat dari aset tetap dan beban kepegawaian. Ketersediaan input ini diharapkan memacu persaingan pasar yang sehat sehingga $A B$ mampu beroperasi secara efisien dalam memperoleh output usaha, seperti komisi jasa Perantara Pedagang Efek (PEE) serta pendapatan usaha lain dari Penjamin Emisi Efek (PEE) dan Manajer Investasi (MI). Analisis DEA membutuhkan variabel input dan output yang digunakan mengukur efisiensi $\mathrm{AB}$ yang disajikan dalam Tabel 2. 


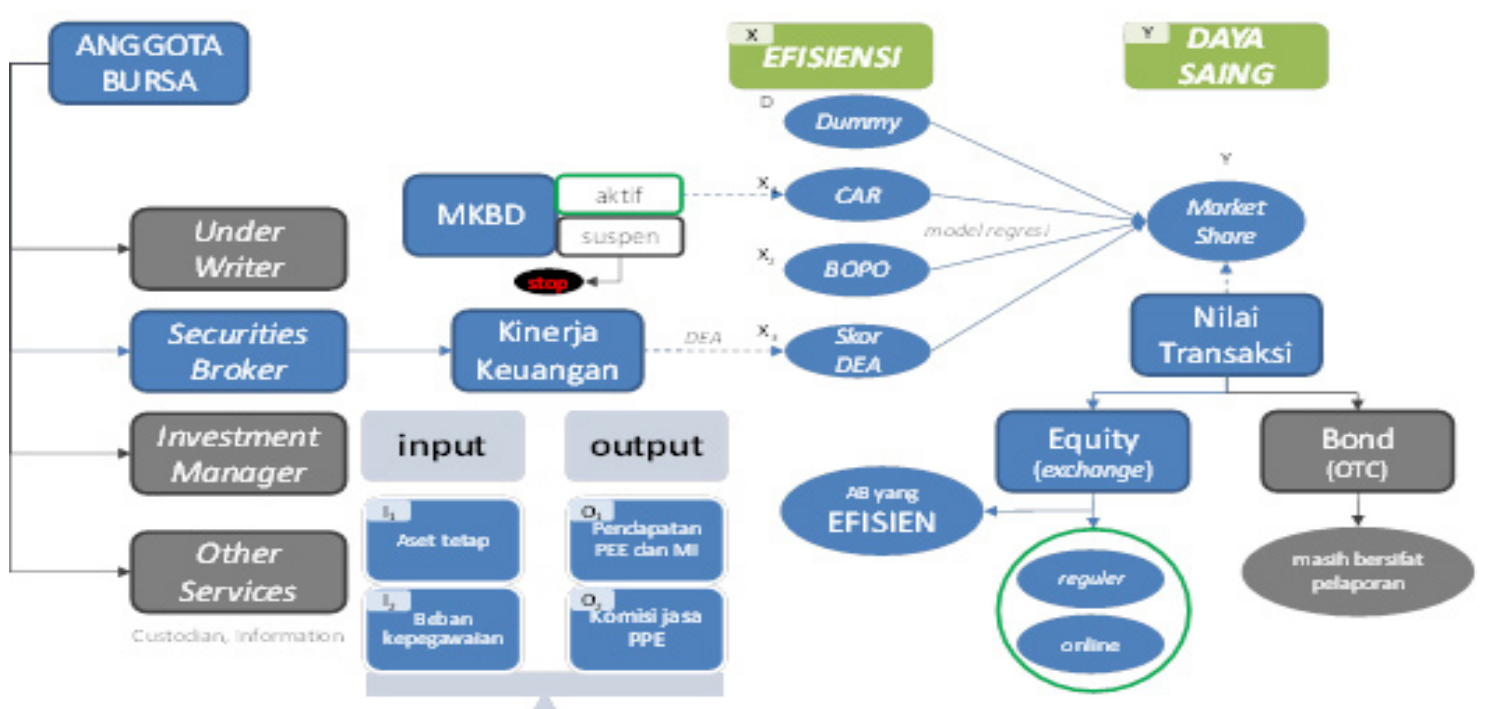

Gambar 2. Kerangka pemikiran penelitian

Tabel 2. Variabel input-output

\begin{tabular}{llll}
\hline & Variabel & \multicolumn{1}{c}{ Definisi } & Sumber \\
\hline Input: & Jumlah dari: & \\
I1 & - Aset tetap & Neraca & \\
I2 & - Beban kepegawaian & Laba rugi & \\
Output: & Jumlah dari: & \\
O1 & - Komisi jasa PPE & Arus kas & \\
O2 & - Pendapatan PEE dan MI & Laba rugi & \\
\hline
\end{tabular}

Variabel input output ini diperoleh dari laporan keuangan $\mathrm{AB}$. Efisiensi $\mathrm{AB}$ diukur dengan menghitung rasio antara output dan input, dengan rumus:

$$
\operatorname{Max} E=\frac{\sum_{j=1}^{2} \mathrm{~m}_{k k} O_{k}}{\sum_{i=1}^{2} v_{k} I_{k}}=\frac{\mathrm{m}_{k} O_{1 k}+\mathrm{m}_{2 k} O_{2 k}}{v_{1 k} I_{1 k}+v_{2 k} I_{2 k}}
$$

Keterangan: E (efisiensi $\mathrm{AB}$ ), $\mathrm{O}_{\mathrm{jk}}$ (output dari ABk), $\mathrm{I}_{\mathrm{ik}}$ (input yang digunakan $\left.\mathrm{ABk}\right), \mu_{\mathrm{jk}}$ (bobot output), $v_{\mathrm{ik}}($ bobot input), $\mathrm{k}$ (jumlah AB dari 1 sampai 97).

Pemantauan tingkat efisiensi $\mathrm{AB}$ akan lebih berarti apabila dikaitkan dengan daya saingnya. Penguasaan pangsa pasar yang ditinjau dari nilai transaksi saham akan mencerminkan daya saing $\mathrm{AB}$ di pasar modal. Identifikasi hubungan daya saing dengan tingkat efisiensi mampu dijelaskan dalam suatu model regresi. Selain itu, tipe $\mathrm{AB}$ juga berpengaruh terhadap daya saing. Tipe AB dijadikan variabel Dummy yang dibedakan berdasarkan jenis kepemilikan (lokal, joint venture), fasilitas yang ditawarkan (reguler, online trading), dan skala perusahaan (kecil, menengah, dan besar). Kebijakan AB joint venture tentu berbeda dengan
AB lokal. AB yang mudah mengikuti perkembangan teknologi terkini dan memenuhi tuntutan nasabah cenderung memiliki daya saing tinggi. Modal besar atau skala perusahaan mutlak dibutuhkan jika $\mathrm{AB}$ ingin memiliki fasilitas online trading dan melakukan inovasi lainnya. Perbedaan tipe $\mathrm{AB}$ ini diduga memberikan efek terhadap daya saing bisnis.

Besarnya efisiensi perusahaan bergantung pada berbagai faktor termasuk karakteristik industri. Sebagai contoh: Widiarti et al. (2015) menyebutkan determinan efisiensi di perbankan dipengaruhi oleh rasio Non Performing Loans (NPL), Loan to Deposit Rasio (LDR), ukuran bank, Cost Efficiency Rasio (CER), dan Capital Adequacy Rasio (CAR). Selain itu, pertumbuhan ekonomi, suku bunga, kapitalisasi pasar, pangsa pasar, permodalan, rasio LDR, Net Interest Margin (NIM), dan kredit juga berpengaruh terhadap efisiensi bank (Muljawan et al. 2014). Variabel yang diduga berpengaruh terhadap daya saing $\mathrm{AB}$ meliputi CAR dan Biaya Operasional per Pendapatan Operasional (BOPO). Penjelasan mengenai variabel independen dalam model regresi sebagai berikut: 
X1 : CAR dalam bisnis transaksi efek dapat diwakili dengan porsi nilai MKBD atau kecukupan modal bagi $\mathrm{AB}$ terhadap ekuitasnya

X2 : BOPO atau operational efficiency merupakan rasio beban operasional terhadap pendapatan operasional.

X3 : Skor DEA digunakan menilai tingkat efisiensi $\mathrm{AB}$ dengan perusahaan sejenis sebagai acuan yang paling optimal

D : Dummy untuk tipe AB yang dibagi menurut jenis kepemilikan (D1), fasilitas AB (D2), dan skala perusahaan (D3)

Keempat variabel ini dilihat pengaruhnya terhadap daya saing $\mathrm{AB}$ yang diukur dari besarnya kontribusi (market share) AB terhadap nilai transaksi saham di BEI yang dirumuskan sesuai model regresi berikut:

$$
\begin{aligned}
\text { Daya Saing }_{i}= & \mathrm{b}_{0}+\mathrm{b}_{1} C A R_{i}+\mathrm{b}_{2} \text { BOPO }_{i}+ \\
& \mathrm{b}_{2} \text { BOPO }_{i}+\mathrm{b}_{3} \text { Skor DEA } A_{i}+\mathrm{b}_{4} D+\mathrm{e}_{i}
\end{aligned}
$$

\section{HASIL}

\section{Gambaran Efisiensi Anggota Bursa}

$\mathrm{AB}$ sebagai bagian lembaga keuangan yang bergerak di pasar modal Indonesia perlu diperhatikan karena dirasa belum optimal dalam memanfaatkan potensi pasar dalam negeri dan peluang pasar bebas ASEAN. Inisiatif memperkuat $\mathrm{AB}$ dalam menghadapi persaingan perlu dipersiapkan dengan baik. AB yang kuat dan berdaya saing terlihat dari kinerja laporan keuangannya. Laporan keuangan $\mathrm{AB}$ memuat seluruh data dan informasi aktivitas bisnis perusahaan selama periode tertentu. Ringkasan laporan keuangan dari 97 AB di BEI disajikan pada Tabel 3.

Kinerja keuangan $\mathrm{AB}$ sempat mengalami penurunan terutama pada Triwulan 3 tahun 2015. Hal ini terlihat dari perkembangan aset dan posisi laba (rugi) usaha $\mathrm{AB}$ yang nilainya cenderung turun bahkan rata-rata mencatat kerugian sekitar Rp1,7 miliar. AB yang efisien akan bertahan saat kondisi pasar kurang mendukung. Terbukti, ada sejumlah AB yang berhasil mencatat laba usaha di akhir tahun 2015. Kinerja AB ini semakin baik ketika pasar merespon positif kebijakan pemerintah pada tahun 2016.

Keterbatasan sumber daya bukan hambatan dalam memaksimalkan hasil usaha jika $\mathrm{AB}$ melakukan bisnis secara efisien. Aset tetap dan beban kepegawaian menjadi indikator sumber daya perusahaan. Rata-rata jumlah aset tetap $\mathrm{AB}$ tidak lebih dari Rp10 miliar sedangkan beban kepegawaian tahun 2015 rata-rata sebesar Rp30 miliar (Gambar 3). Sumber daya (input) ini harus digunakan untuk memperoleh output yang sebanding. Komisi jasa PPE hampir sama besarnya dengan beban kepegawaian, selisihnya berkisar antara Rp2-4 miliar (Gambar 4). Kondisi bisnis ini sepertinya terlihat menguntungkan namun sisa komisi jasa PPE ditambah pendapatan PEE dan MI ternyata kadang belum cukup menutupi beban usaha $\mathrm{AB}$.

\begin{tabular}{|c|c|c|c|c|c|c|c|c|}
\hline \multirow{2}{*}{$\begin{array}{c}\text { Akun } \\
\text { (miliar Rp) }\end{array}$} & & \multicolumn{4}{|c|}{ Tahun 2015} & \multicolumn{3}{|c|}{ Tahun 2016} \\
\hline & & TW 1 & TW 2 & TW 3 & TW 4 & TW 1 & TW 2 & TW 3 \\
\hline \multirow[t]{2}{*}{ Aset } & mean & 488,3 & 423,6 & 415,7 & 418,9 & 484,7 & 592,8 & 515,1 \\
\hline & stdev & 535,8 & 449,7 & 419,1 & 479,7 & 544,8 & 730,5 & 586,7 \\
\hline \multirow[t]{2}{*}{ Liabilitas } & mean & 256,6 & 199,6 & 199,8 & 194,7 & 254,7 & 364,8 & 277,2 \\
\hline & stdev & 328,6 & 259,2 & 241,5 & 303,5 & 362,7 & 542,4 & 394,1 \\
\hline \multirow[t]{2}{*}{ Ekuitas } & mean & 231,6 & 224,1 & 215,9 & 224,1 & 230,0 & 228,0 & 237,9 \\
\hline & stdev & 255,2 & 237,3 & 235,1 & 245,9 & 255,4 & 247,4 & 255,9 \\
\hline \multirow[t]{2}{*}{ Pendapatan Usaha } & mean & 18,2 & 30,5 & 38,3 & 64,6 & 16,9 & 35,5 & 58,5 \\
\hline & stdev & 29,5 & 48,2 & 67,5 & 97,6 & 27,4 & 55,5 & 90,9 \\
\hline \multirow[t]{2}{*}{ Beban Usaha } & mean & 13,3 & 27,9 & 39,9 & 57,4 & 12,6 & 27,3 & 42,8 \\
\hline & stdev & 18,2 & 38,4 & 55,3 & 80,8 & 18,6 & 40,1 & 62,7 \\
\hline \multirow[t]{2}{*}{ Laba (Rugi) Usaha } & mean & 4,9 & 2,6 & $-1,7$ & 7,2 & 4,3 & 8,2 & 15,7 \\
\hline & stdev & 16,9 & 18,0 & 26,8 & 31,6 & 14,3 & 25,1 & 41,5 \\
\hline
\end{tabular}

Tabel 3. Ringkasan laporan keuangan $\mathrm{AB}$ 
Upaya mendorong $\mathrm{AB}$ agar lebih efisien dalam menjalankan bisnis menjadi suatu inisiatif yang tepat. Tantangan dan peluang dari bisnis transaksi efek ke depan akan semakin ketat. Seluruh pelaku pasar harus bersinergi untuk mencapai kemajuan pasar modal Indonesia. Pengukuran efisiensi $\mathrm{AB}$ melalui analisis DEA akan lebih berguna dalam menentukan kondisi bisnis. Hasil analisis DEA disajikan dalam Gambar 5.

Efisiensi AB selama tahun 2015-2016 belum mengalami peningkatan yang nyata. Rata-rata efisiensi AB pada Triwulan 3 tahun 2016 berada pada nilai 0,22 dengan jumlah $\mathrm{AB}$ yang efisien tidak lebih dari 10 perusahaan. Tingkat efisiensi ini tergolong rendah atau menunjukkan sumber daya yang ada belum dikelola secara optimal. Selain itu, sedikitnya AB yang efisien menandakan bahwa kelangsungan bisnis $\mathrm{AB}$ perlu diperhatikan. Penyebaran $\mathrm{AB}$ berdasarkan tingkat efisiensinya disajikan dalam Gambar 6. AB yang efisiensinya rendah atau di bawah 0,20 mencapai lebih dari $60 \%$. Akibatnya industri transaksi efek sulit berkembang dan kelangsungan bisnis $\mathrm{AB}$ terancam. Untuk itu, identifikasi tipe $A B$ perlu dilakukan untuk mengetahui arah bisnis yang ideal dan efisien.

Anggota Bursa ( $\mathrm{AB}$ ) yang menawarkan fasilitas online trading diperkirakan tingkat efisiensinya lebih baik dibandingkan $\mathrm{AB}$ reguler. Skala perusahaan yang dibagi menurutjumlah asetnya diprediksi ikut berpengaruh. $\mathrm{AB}$ joint venture yang umumnya berskala besar seharusnya lebih efisien daripada $\mathrm{AB}$ lokal yang mayoritas asetnya terbatas. Hal itu perlu dibuktikan melalui data efisiensi berdasarkan tipe $\mathrm{AB}$ yang disajikan pada Tabel 4.

Anggota Bursa ( $\mathrm{AB}$ ) joint venture jumlahnya lebih sedikit daripada $\mathrm{AB}$ lokal namun lebih dari $20 \%$ termasuk $\mathrm{AB}$ yang efisien. Skor efisiensi $\mathrm{AB}$ joint venture juga terlihat lebih baik, yakni 0,40. Begitu juga dengan $\mathrm{AB}$ online trading atau $\mathrm{AB}$ berskala besar umumnya kedua tipe $A B$ ini relatif lebih efisien dibanding AB lainnya.

Perusahaan yang efisien memiliki daya saing yang relatif tinggi dan bisa menjadi pemimpin pasar (market leader) pada suatu industri. Semakin efisien suatu $A B$ diharapkan daya saingnya juga semakin tinggi. Tingkat efisiensi dan daya saing AB disajikan dalam Tabel 5.

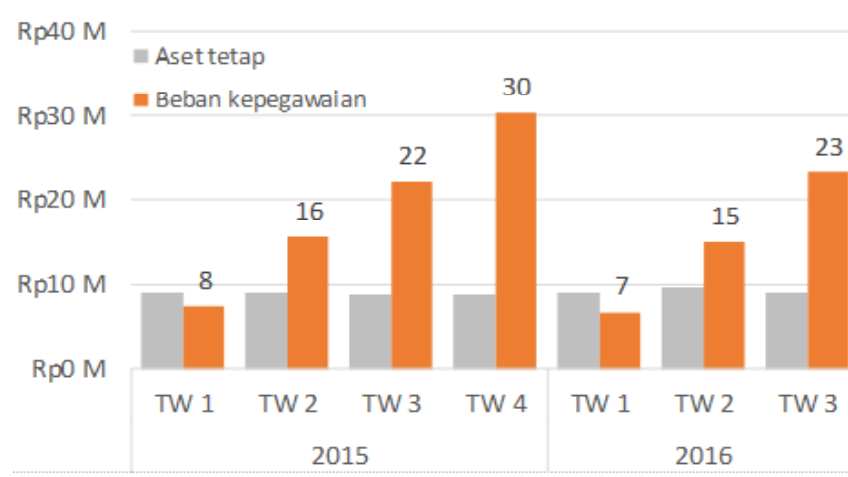

Gambar 3. Perkembangan aset tetap dan beban kepegawaian

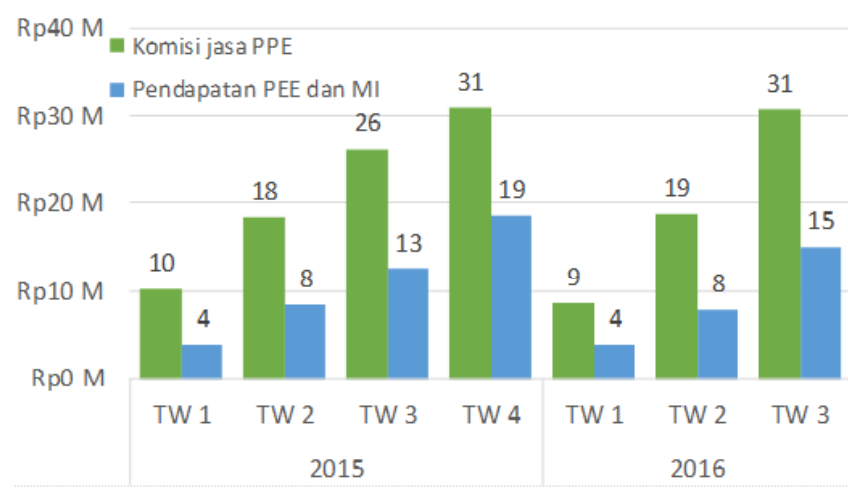

Gambar 4. Perkembangan komisi jasa PPE serta pendapatan PEE dan MI
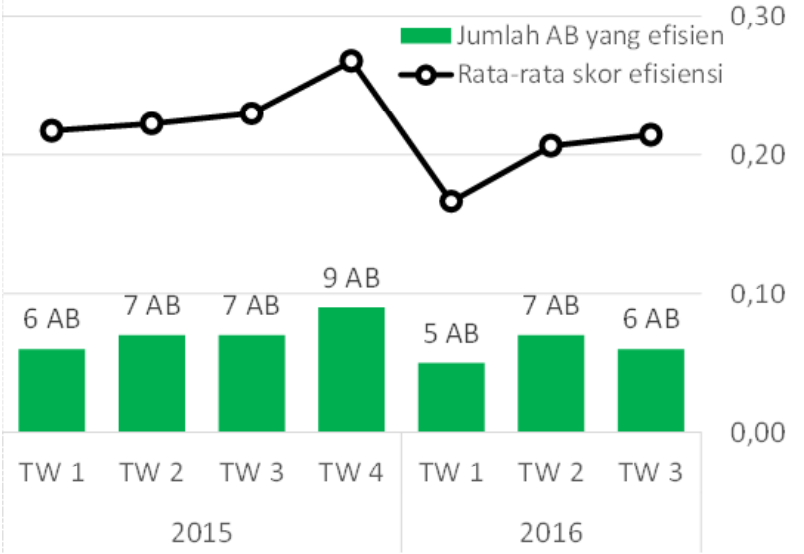

Gambar 5. Perkembangan efisiensi AB

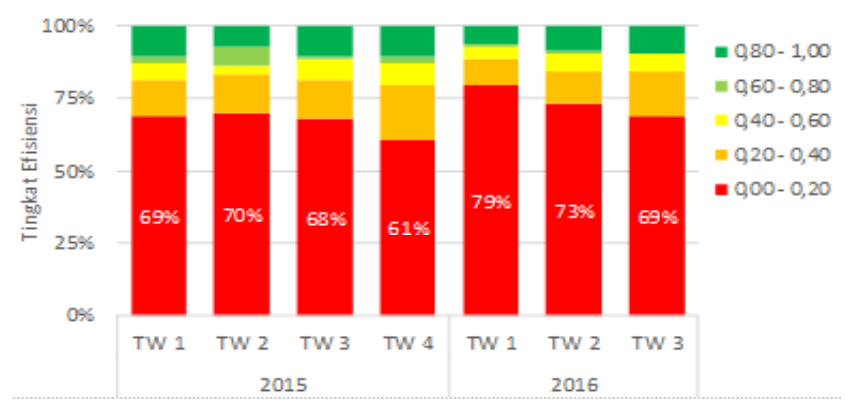

Gambar 6. Penyebaran AB berdasarkan tingkat efisiensinya 
Tabel 4. Efisiensi berdasarkan tipe $\mathrm{AB}$ per Triwulan 4 tahun 2015 (audited)

\begin{tabular}{|c|c|c|c|}
\hline Tipe AB & $\mathrm{N}$ & Skor & $\mathrm{AB}$ yang efisien \\
\hline \multicolumn{4}{|l|}{ Kepemilikan } \\
\hline Lokal & 74 & 0,23 & $4 \quad(5,4 \%)$ \\
\hline Joint venture & 23 & 0,40 & $5(21,7 \%)$ \\
\hline \multicolumn{4}{|c|}{ Fasilitas transaksi } \\
\hline Reguler & 33 & 0,21 & $2 \quad(6,1 \%)$ \\
\hline Online trading & 64 & 0,30 & $7(10,9 \%)$ \\
\hline \multicolumn{4}{|c|}{ Skala perusahaan } \\
\hline Kecil & 23 & 0,11 & $0 \quad(0,0 \%)$ \\
\hline Menengah & 47 & 0,24 & $3 \quad(6,4 \%)$ \\
\hline Besar & 27 & 0,45 & $6(22,2 \%)$ \\
\hline
\end{tabular}

Tabel 5. Perbandingan pangsa pasar pada beberapa tingkat efisiensi $\mathrm{AB}$

\begin{tabular}{llll}
\hline \multirow{2}{*}{ Tingkat efisiensi } & \multirow{2}{*}{ Jumlah } & \multicolumn{2}{c}{ Pangsa pasar } \\
\cline { 3 - 4 } & AB & Rata-rata & Std. Dev. \\
\hline $0,00-0,20$ & 59 & $0,51 \%$ & $0,79 \%$ \\
$0,20-0,40$ & 18 & $1,55 \%$ & $1,73 \%$ \\
$0,40-0,60$ & 8 & $1,73 \%$ & $1,64 \%$ \\
$0,60-0,80$ & 2 & $1,36 \%$ & $1,55 \%$ \\
$0,80-1,00$ & 10 & $2,22 \%$ & $2,11 \%$ \\
\hline
\end{tabular}

Ada kecenderungan tingkat efisiensi yang tinggi diraih $\mathrm{AB}$ dengan pangsa pasar yang besar. Hal ini terlihat dari $\mathrm{AB}$ dengan efisiensi lebih dari 0,80 , pangsa pasarnya rata-rata $2,22 \%$. Sebaliknya, AB dengan efisiensi di bawah 0,20 , pangsa pasarnya hanya sekitar $0,51 \%$.

\section{Hubungan Efisiensi dengan Daya Saing}

Hubungan antara efisiensi dengan daya saing sebaiknya tidak hanya dilihat secara deskriptif, namun juga diestimasi melalui model regresi agar dapat dijelaskan dengan baik. Pemodelan harus memenuhi kriteria kebaikan model, signifikansi parameter, dan beberapa pengujian asumsi. Kriteria pemilihan model regresi terbaik, yakni Mean Square Error (MSE) minimum dan Koefisien determinasi $\left(\mathrm{R}^{2}\right)$ maksimum.

Semakin besar koefisien R2, semakin baik model yang dihasilkan karena menjelaskan lebih banyak titik data (Drapper \& Smith, 1996). Terdapat dua pengujian signifikansi parameter regresi, yaitu pengujian parameter secara simultan dengan statistik uji $\mathrm{F}$ dan parsial dengan statistik uji t. Selain itu, asumsi residual yang harus dipenuhi meliputi Identik, Independen dan Distribusi Normal (IIDN). Estimasi model regresi menggunakan data pada satu posisi (31 Desember
2015) dengan pertimbangan lebih akurat karena telah diaudit.

Tahap pemilihan model regresi terbaik diawali dari evaluasi arah hubungan dan signifikansi parameter pada alpha 0,05 . Model regresi dengan seluruh variabel (Model 1 )melalui metode Ordinary Least Square (OLS) diperoleh parameter variabel BOPO (X2) dan fasilitas (D2) yang tidak signifikan. Hasil pengujian asumsi residual ditemukan ada indikasi heterokesdastisitas sehingga perlu dilakukan pemodelan ulang terboboti menggunakan metode Weighted Least Square (WLS).

Menurut Gujarati (1992), pembobot yang digunakan dalam model regresi terboboti dapat berupa $1 / \sigma^{2}$ (varian residual) untuk mengatasi kasus heterokesdastisitas. Hasil pemodelan ulang (Model 2 ) diperoleh bahwa ada satu parameter yang tetap tidak signifikan. Koefisien X2 bernilai negatif yang disebabkan kasus multikolinieritas sehingga perlu dikeluarkan dari model 2. Model tanpa variabel BOPO (Model 3) merupakan model regresi terboboti terbaik dengan nilai adj $\mathrm{R}^{2}$ sebesar 93,76 dan asumsi residual dipenuhi semuanya. Tahap pemilihan model regresi terbaik disajikan pada Tabel 6. Untuk memastikan asumsi residual telah terpenuhi disajikan pada Gambar 7. Persamaan model regresi terboboti untuk menjelaskan daya saing $\mathrm{AB}$ sebagai berikut:

$$
\begin{aligned}
Y=-0,0096+0,0086 X_{1}+0,0064 X_{3}+0,0081 D_{1}+ \\
\quad 0,0021 D_{2}+0,0078 D_{3}+\mathrm{e}_{i}
\end{aligned}
$$

Daya saing (Y) memiliki hubungan dengan kecukupan modal $\left(\mathrm{X}_{1}\right)$ dan efisiensi AB $\left(\mathrm{X}_{3}\right)$. Kecukupan modal akan menambah kemampuan $\mathrm{AB}$ memanfaatkan peluang bisnis yang ada demi pangsa pasar yang lebih luas sedangkan efisiensi lebih ke arah cara pengelolaan sumber daya atau modal perusahaan untuk hasil yang optimal. Tipe $\mathrm{AB}$ membantu pemahaman daya saing yang komprehensif dari jenis kepemilikan $\left(D_{1}\right)$, fasilitas transaksi $\left(\mathrm{D}_{2}\right)$, dan skala perusahaan $\left(\mathrm{D}_{3}\right)$.

\section{Batasan Anggota Bursa yang Kompetitif}

Anggota Baru (AB) joint venture relatif kompetitif karena modalnya kuat dan dikelola dengan baik. Fasilitas transaksi (reguler atau online trading) juga dapat membedakan daya saing AB. Namun, relatif kecil pengaruhnya. Peningkatan skala perusahaan justru akan membuat $\mathrm{AB}$ lokal lebih kompetitif dan setara dengan $\mathrm{AB}$ joint venture. Pemetaan daya saing berdasarkan tipe $\mathrm{AB}$ bisa dilihat dalam Gambar 8 . 
Tabel 6. Pemilihan model regresi terbaik

\begin{tabular}{llccc}
\hline & Variabel & Model 1 & Model 2 & Model 3 \\
\hline X0 & Intersep & $-1,133 \mathrm{e}-02^{* * *}$ & $-9,656 \mathrm{e}-03^{* * *}$ & $-0,0095593^{* * *}$ \\
X1 & CAR & $9,477 \mathrm{e}-03^{* * *}$ & $8,493 \mathrm{e}-03^{* * *}$ & $0,0085852^{* * *}$ \\
X2 & BOPO & $2,248 \mathrm{e}-05^{* * *}$ & $-8,112 \mathrm{e}-07^{* * *}$ & \\
X3 & Skor DEA & $7,909 \mathrm{e}-03^{* * *}$ & $6,210 \mathrm{e}-03^{* * *}$ & $0,0063623^{* * *}$ \\
D1 & Kepemilikan & $8,244 \mathrm{e}-03^{* * *}$ & $8,071 \mathrm{e}-03^{* * *}$ & $0,0081181^{* * *}$ \\
D2 & Fasilitas & $2,487 \mathrm{e}-03^{* * *}$ & $2,123 \mathrm{e}-03^{* * *}$ & $0,0021164^{* * *}$ \\
D3 & Skala & $8,779 \mathrm{e}-03^{* * *}$ & $7,999 \mathrm{e}-03^{* * *}$ & $0,0078494^{* * *}$ \\
& MSE & 0,0000770 & 0,88 & 0,85 \\
& Adj R2 & 63,04 & 96,61 & 93,76 \\
\hline
\end{tabular}

Keterangan: tingkat signifikansi: ‘***’ $0,001^{\text {‘ } * * ’} 0,01^{\text {‘*’ }} 0,05^{\prime} . ’ 0,1^{\text {‘ ’ } 1}$

Series resi.wis
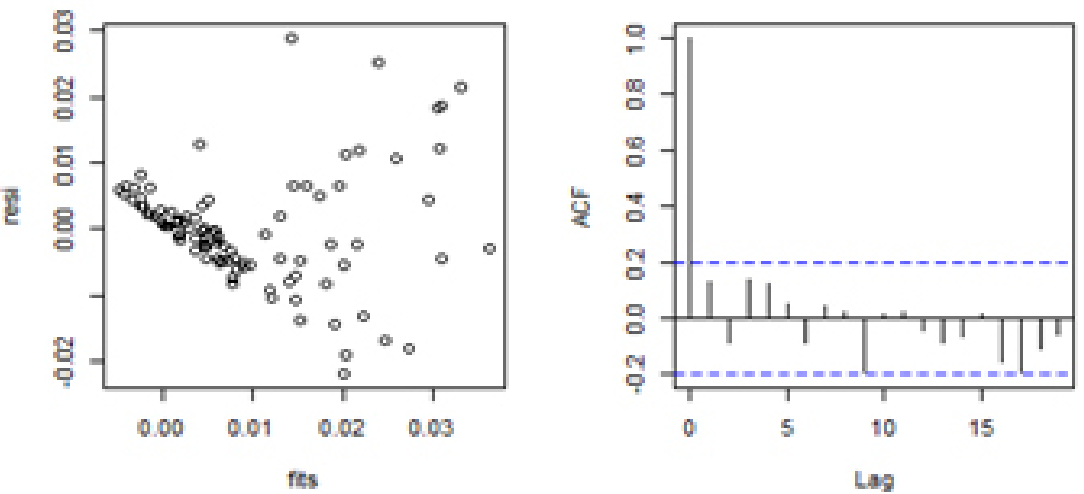

Normal Q.Q.Plot

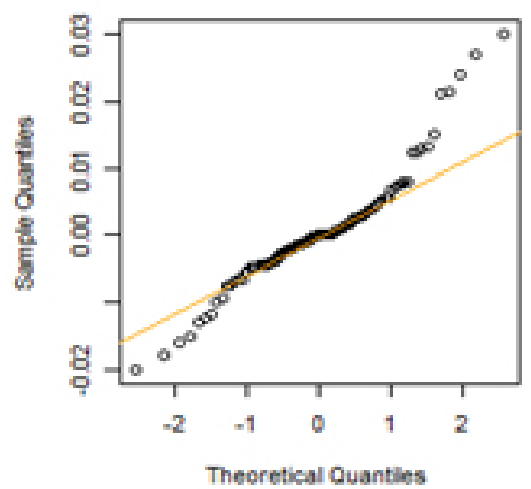

Gambar 7. Pemeriksaan asumsi residual secara visual

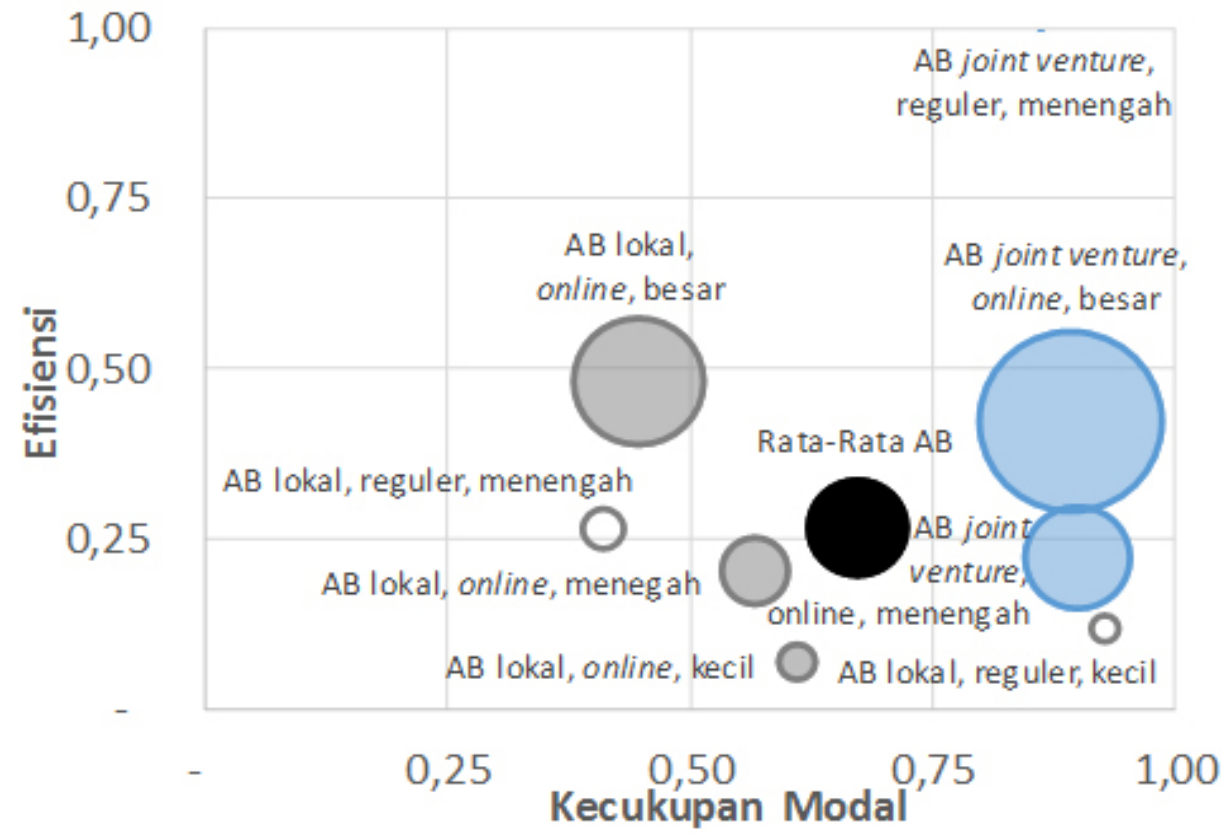

Gambar 8. Pemetaan daya saing berdasarkan tipe $\mathrm{AB}$ 
Besarnya lingkaran menggambarkan daya saing atau pangsa pasar AB. Kecukupan modal pada sumbu $X$ sedangkan efisiensi dijadikan sumbu Y. Pemetaan AB tersebut menjelaskan bahwa skala perusahaan yang diikuti pengelolaan $A B$ yang efisien akan membuat $A B$ lebih kompetitif. Informasi serupa diungkapkan Abidin dan Cabanda (2011) yang meneliti industri asuransi dan hasilnya menunjukkan bahwa perusahaan dengan skala besar lebih efisien daripada perusahaan kecil.

Anggota Bursa (AB) lokal mampu bersaing dengan $\mathrm{AB}$ joint venture pada skala perusahaan yang sama, terlebih lagi memiliki kecukupan modal dan fasilitas online trading. Hadad et al. (2008) juga memperoleh kesimpulan yang sama pada industri perbankan Indonesia. Dalam penelitiannya dinyatakan bahwa semakin besar ukuran bank, maka semakin efisien mendukung kebijakan konsolidasi perbankan. Surifah (2011) mengungkapkan bahwa perusahaan besar memiliki sumber daya yang lebih baik, biaya transaksi yang lebih rendah, serta mampu bertahan dalam menghadapi persaingan dan perekonomian yang kurang menentu.

Kecukupan modal mendorong $\mathrm{AB}$ untuk mencapai efisiensi yang lebih baik dan memberikan pengaruh yang positif terhadap daya saing. Kecukupan modal sebagai sumber daya perusahaan harus dikelola secara efisien agar terbentuk AB yang kompetitif. Perusahaan yang efisien secara internal akan membuat keputusan investasi secara efisien (Ye, 2009).

Kekuatan modal $\mathrm{AB}$ diduga belum cukup (relatif terbatas) sehingga kurang maksimal dalam menangkap peluang usaha. Nilai minimum MKBD belum memadai untuk menciptakan bisnis yang sehat. Persyaratan MKBD yang harus dipenuhi AB minimal Rp25 miliar atau $6,25 \%$ dari total liabilitas tanpa utang sub-ordinasi dan utang dalam rangka penawaran umum atau penawaran terbatas ditambah ranking liabilities. Inisiatif penguatan modal $\mathrm{AB}$ diperkirakan dapat mendorong efisiensi di pasar modal. Batas minimum MKBD perlu ditingkatkan agar mampu bersaing dengan bursa lain dan mencapai target nilai transaksi.

Menurut Hendarwin (2015) keberhasilan pasar modal dipengaruhi beberapa faktor, yakni kekuatan permintaan dan penawaran pasar, pertumbuhan ekonomi, iklim politik, dan peran lembaga pendukung seperti $\mathrm{AB}$.
Keahlian dan permodalan menjadi syarat penting bagi $\mathrm{AB}$ mengingat pasar modal termasuk industri yang sangat teknis dan padat modal (Moechidie dan Ramelan, 2012). Batasan MKBD yang mendukung bisnis AB di Indonesia diusulkan berubah dari Rp25Rp100 miliar. Kenaikan ini tentu mendorong AB untuk menambah modal dan memacu daya saing $A B$ pada efisiensi tertentu agar setara dengan bursa lain. Hal ini mengingat persyaratan modal di bursa lain cukup besar dibandingkan dengan syarat di BEI yang disajikan dalam Tabel 7.

Tabel 7. Perbandingan persyaratan modal di berbagai bursa

\begin{tabular}{lll}
\hline \multirow{2}{*}{ Bursa } & \multicolumn{2}{c}{ Modal Minimum } \\
\cline { 2 - 3 } & \multicolumn{1}{c}{ Lokal } & \multicolumn{1}{c}{ USD } \\
\hline BEI & Rp30 miliar & USD 2 juta \\
BM & RM20 juta & USD 5 juta \\
SGX & SGD 200 juta & USD 150 juta \\
SET & 500 juta Baht & USD 15 juta \\
PSE & PHP 30 juta & USD 630 ribu \\
\hline
\end{tabular}

Menurut Porter (1985), efisiensi termasuk strategi bersaing yang sesuai digunakan pada pasar yang umum dengan produk yang hampir sama. Salah satu bentuk yang sesuai dengan strategi efisiensi di pasar modal Indonesia adalah memperkuat $\mathrm{AB}$ dengan menggabungkan (merger) AB yang memiliki MKBD rendah, selain opsi penambahan modal (Dwijayanto dan Cicilia, 2015). Benarda et al. (2016) menekankan bahwa merger atau akuisisi dapat dilakukan agar efisiensi permanfaatan sumber daya dapat tercapai. Penyesuaian persyaratan MKBD memaksa AB mencari tambahan modal baru. Oleh karena itu, skema penambahan modal perlu dipertimbangkan $A B$, seperti IPO, merger, aksi korporasi, penerbitan hutang subordinasi, dan pembentukan lembaga pembiayaan.

Regulasi dan kebijakan AB ke depan perlu diarahkan untuk mendorong penguatan $\mathrm{AB}$ sehingga mampu melakukan inovasi dan melayani pasar yang luas. AB sebaiknya fokus pada bisnisnya sebagai broker sebab potensinya masih besar dan belum dikelola secara optimal. Masyarakat dihimbau lebih hati-hati menentukan $\mathrm{AB}$ terutama yang modalnya terbatas sebagai penyedia jasa transaksi efek. Pengelola dana investasi disarankan melibatkan $\mathrm{AB}$ dengan kredibilitas bagus dan modal yang kuat agar terhindar dari risiko pasar. 


\section{Implikasi Manajerial}

Hasil analisis dan temuan dalam peneltian ini akan memberikan implikasi managerial yang berarti, terutama bagi $\mathrm{AB}$ dan regulator pasar modal di Indonesia. Beberapa implikasi managerial kepada pihak terkait, diantaranya:

1. Bagi $A B$, kecukupan modal yang kuat terbukti bisa meningkatkan daya saing bisnis perusahaan agar mampu memanfaatkan peluang dari pasar bebas. Hal ini diperlukan karena sumber daya yang dikelola dengan baik menjadi modal perusahaan untuk memperoleh pendapatan yang lebih besar. Efisiensi akan tercapai pada skala tertentu apabila perusahaan fokus mengembangkan bisnis utama dan memperluas pangsa pasarnya. Seluruh usaha AB ini membutuhkan komitmen dan kesediaan manajemen berkonsolidasi dengan $\mathrm{AB}$ lain demi menjaga pasar modal yang sehat dan semakin kompetitif dengan bursa lain.

2. Bagi BEI dan OJK sebagai regulator pasar modal Indonesia harus siap dalam menghadapi berbagai perubahan dan mampu merespon setiap permasalahan secara tepat. Potensi pasar bebas ASEAN sangat besar karena kinerja emiten di BEI menjadi daya tarik bagi investasi asing masuk ke Indonesia. Namun, kesempatan ini tidak akan berhasil dimanfaatkan untuk menambah transaksi di bursa tanpa peningkatan kapasitas $\mathrm{AB}$ melalui kenaikan persyaratan nilai MKBD. Penyesuaian batasan nilai MKBD dalam rangka penguatan peran $\mathrm{AB}$ merupakan inisiatif yang perlu didukung oleh seluruh pelaku pasar.

Pemantauan efisiensi tidak kalah pentingnya dengan evaluasi persyaratan kecukupan modal AB. Nilai MKBD dievaluasi berdasarkan laporan yang dikirim $\mathrm{AB}$ setiap hari sedangkan pemantauan efisiensi baru dapat dilaksanakan ketika laporan keuangan AB keluar (triwulanan).

\section{KESIMPULAN DAN SARAN}

\section{Kesimpulan}

Efisiensi $\mathrm{AB}$ relatif rendah sekitar 0,22 dengan $\mathrm{AB}$ yang efisiensinya rendah atau di bawah 0,20 mencapai lebih dari $60 \%$. Hal ini menunjukkan bahwa sumber daya dan potensi ekonomi Indonesia belum optimal dimanfaatkan sektor pasar modal. $\mathrm{AB}$ online trading atau $\mathrm{AB}$ berskala besar umumnya relatif lebih efisien daripada AB lain. Semakin efisien suatu AB diharapkan daya saingnya juga semakin tinggi.

Hubungan antara efisiensi AB dengan daya saing bisnis berbanding lurus. Selain itu, kecukupan modal ternyata berpengaruh pada daya saing bisnis. $\mathrm{AB}$ yang memiliki MKBD besar cenderung lebih kompetitif dibandingkan AB dengan MKBD terbatas. Persyaratan MKBD sebesar Rp25 miliar dipandang perlu disesuaikan dengan batas modal minimum di bursa lain. Kenaikan minimum MKBD menjadi Rp100 miliar diharapkan membuat $\mathrm{AB}$ lebih kompetitif .

\section{Saran}

Penelitian terkait efisiensi dan daya saing $A B$ sangat dibutuhkan mengingat adanya keterbatasan dan banyaknya kekurangan dalam penelitian ini. Penambahan variabel dan periode data yang lebih panjang sangat dianjurkan agar diperoleh informasi yang lebih komprehensif. Selain itu, penggunaan metode analisis data yang berbeda juga akan memperkaya pemahaman mengenai bisnis transaksi efek.

\section{DAFTAR PUSTAKA}

Abidin Z, Cabanda E. 2011. Efficiency of non-life insurance in Indonesia. Journal of Economics Business and Accountancy Ventura 14(3): 197202. https://doi.org/10.14414/jebav.v14i3.46.

Abidin Z, Endri. 2009. Kinerja efisiensi teknis bank pembangunan daerah: pendekatan Data Envelopment Analysis (DEA). Jurnal Akuntansi dan Keuangan 11(1):21-29.

Agus SS. 2011. Pengaruh pertumbuhan modal dan aset terhadap Rasio Risk Based Capital (RBC), pertumbuhan premi neto dan profitabilitas perusahaan asuransi umum di Indonesia. Pekbis Jurnal 3(1): 391-405.

Aris A. 2016. Spektrum Bisnis: Obat Kuat Untuk Anggota Bursa. http://koran.bisnis.com/ $\mathrm{read} / 20160218 / 270 / 520215 /$ spektrum-bisnisobat-kuat-untuk-anggota-bursa. [27 April 2016]

Benarda, Sumarwan U, Hosen M. 2016. Tingkat efisiensi industri asuransi jiwa syariah menggunakan pendekatan Two Stage Data Envelopment Analysis. Jurnal Aplikasi Bisnis dan Manajemen 2(1): 64-72.

Diana Y. 2010. Efisiensi dan pelaksanaan hukum 
persaingan usaha. Jurnal Persaingan Usaha 3: 212-120.

Drapper N, Smith H. 1996. Applied Regression Analysis (2nd ed.). New York: John Wiley \& Sons, Chapman and Hall.

Dwijayanto A, Cicilia S. 2015. Masih ada waktu memperkuat pasar lokal. http://lipsus.kontan. co.id/v2/mea/read/287/Masih-ada-waktumemperkuat-pasar-lokal. [26 April 2016]

Gujarati D. 1992. Essentials of Econometrics. New York: McGraw-Hill, Inc.

Hadad MD, Hall MJB, Kenjegalieva K, Santoso W, Satria R, Simper R. 2008. Efficiency in Indonesian Banking: Recent Evidence. United Kingdom: Loughborough University.

Hadad M, Santoso W, Ilyas D, Mardanugraha E. 2003. Analisis Efisiensi Industri Perbankan Indonesia: Penggunaan Metode Nonparametrik Data Envelopment Analysis (DEA). Jakarta, Indonesia: Bank Indonesia.

Hendarwin R. 2015. Hubungan Efisiensi Pasar Modal di Indonesia Menghadapi Masyarakat Ekonomi ASEAN (MEA) 2015. Sukabumi: BPK.

Moechidie A, Ramelan H. 2012. Gerbang Pintar Pasar Modal: Bukunya Investor dan Profesional Pasar
Modal. Jakarta: PT. Capital Bridge Advisory. Muljawan D, Hafidz J, Astuti R, Oktapiani R. 2014. Faktor-Faktor Penentu Efisiensi Perbankan Indonesia serta Dampaknya terhadap Perhitungan Suku Bunga Kredit. Jakarta: Bank Indonesia.

Porter ME. 1985. Competitive Advantage - Creating and Sustaining Superior Performance. New York: Free Press.

Subandi, Ghozali I. 2013. Determinan efisiensi dan dampaknya terhadapkinerja profitabilitas industri perbankan di Indonesia. Jurnal Keuangan dan Perbankan 17(1): 123-135.

Surifah. 2011. Kepemilikan ultimat, tingkat risiko, efisiensi, dan kinerja industri perbankan di Indonesia. Jurnal Siasat Bisnis 15: 37-53.

Widiarti A, Siregar H, Andati T. 2015. The determinants of bank's efficiency in Indonesia. Buletin Ekonomi Moneter dan Perbankan 18(2): 129 156. https://doi.org/10.21098/bemp.v18i2.520.

Ye M. 2009. Efficiency of internal capital allocation and the success of acquisitions. University of New Orleans Theses and Dissertations Paper 1106. 